\title{
Southern Canada's crisis ecoregions: identifying the most significant and threatened places for biodiversity conservation
}

\author{
Daniel Kraus ${ }^{1,2}$ (D) Andrea Hebb ${ }^{1}$
}

Received: 25 July 2019/Revised: 10 August 2020/Accepted: 12 August 2020/

Published online: 27 August 2020

(C) The Author(s) 2020

\begin{abstract}
Identifying and protecting key areas for biodiversity is a cornerstone of effective nature conservation. This conservation assessment analyzes 77 ecoregions across the southern, settled part of Canada to identify priorities for conservation action. Our analysis included 34 measures of biodiversity, threat and conservation response. We categorized all ecoregions based on their overall biodiversity and threat scores. This categorization identified nine "crisis ecoregions." These ecoregions have higher biodiversity and threat scores compared to other ecoregions in the study area. These ecoregions represent less than 5\% of Canadian lands and inland waters but provide habitat for over $60 \%$ of Canada's species at risk. Twenty-one ecoregions have higher biodiversity but lower threat scores. Primarily distributed in the more intact portions of the study area, these ecoregions generally have lower biodiversity scores for species diversity, but score very high for intactness, habitat diversity and congregatory species. This assessment can help to contextualize existing and proposed conservation actions by highlighting key biodiversity, threat and conservation attributes of ecoregions across southern Canada. Our assessment can be used to focus efforts on new protected areas, species at risk recovery, capacity building and ecological monitoring. The results of the conservation assessment can be applied to set and track progress toward national, regional and organizational conservation goals, including post-2020 biodiversity targets. Regular reanalysis of the ecoregions to track their trends in biodiversity, threat and conservation responses will support monitoring the effectiveness of conservation programs and highlight ecoregions where continued focus is most needed to conserve Canada's biodiversity.
\end{abstract}

Keywords Conservation assessment $\cdot$ Aichi Target $11 \cdot$ Connectivity $\cdot$ Species at risk $\cdot$ Representation $\cdot$ Protected areas

Communicated by Karen E. Hodges.

This article belongs to the Topical Collection: Biodiversity protection and reserves.

Electronic supplementary material The online version of this article (https://doi.org/10.1007/s10531-02002038-x) contains supplementary material, which is available to authorized users.

Extended author information available on the last page of the article 


\section{Introduction}

Over the last 150 years, biodiversity in Canada has been declining. The decline in species and habitats has been particularly acute in the southern areas of Canada, which have the longest history of colonization, agricultural, urban and industrial land uses, and where most Canadians live. For example, only $25 \%$ of Canada's prairies remain, southern Ontario has lost $85 \%$ of its forest cover and $70 \%$ of southern British Columbia's estuary marshes have been lost or degraded (Federal Provincial and Territorial Governments of Canada 2010).

Habitat loss is the main threat to wildlife in Canada, including species at risk (McCune et al. 2013; Venter et al. 2006). Canada has 724 wildlife species at risk, an increase of over 200 in just the last decade alone (COSEWIC 2016). Many other wildlife populations are declining (WWF Canada 2017). For example, Canadian breeding bird populations have decreased 12\% since 1970, and some bird groups, such as grassland birds, aerial insectivores and shorebirds, are showing steep declines of up to $70 \%$ (NABCI 2012).

While northern Canada still contains vast areas of forest, wetland and tundra, including some of the planet's last areas of wilderness (Watson et al. 2018), the amount of habitat loss in southern Canada is similar to other settled landscapes around the world (Watson et al. 2016). Protection of Canada's north offers some of the last global opportunities to conserve large, intact landscapes; however, the urgency for conservation is greatest in the south where the human footprint is the highest and continues to expand.

The identification of important areas to protect biodiversity is a cornerstone of effective conservation. Place-based conservation priorities that are founded on an assessment of biodiversity, threat and existing conservation responses can be used to provide context for existing efforts, guide funding opportunities and support planning for future conservation action.

Over the last two decades, the ability to carry out systematic conservation assessments at broad geographic scales has advanced through the availability of new analytic tools and comprehensive datasets. Information on land use and land use change, species ranges, rare species and existing conservation lands can be used to assess gaps in protected areas (Jenkins et al. 2015). Assessments over large geographical scales have also highlighted gaps in connectivity (McGuire et al. 2016) and representation of species in protected areas (Wiersma and Nudds 2009) and ecoregions (Parks Canada 2016). Global assessments have shown mismatches between conservation actions and areas for migratory birds (e.g. Runge et al. 2015) and freshwater species (e.g. Darwall et al. 2011).

Comprehensive conservation assessments have been completed in many countries including the United States (Jenkins et al. 2015), Kenya (Habel et al. 2016) and Australia (Natural Resource Management Ministerial Council 2010). The Nature Conservancy of Canada (NCC), The Nature Conservancy and partners developed ecoregional assessments for parts of southern Canada that have helped to drive the work of NCC since the early 2000s, but these assessments are regionally based (Anderson et al. 2006; Gratton 2010; Henson et al. 2005; Riley et al. 2007). Other ecoregional assessments have been done for some parts of Canada, such as the Northern Appalachian/Acadian Ecoregion (Trombulak et al. 2008) and southern Ontario (ECCC 2014), and for freshwater ecosystems (World Wildlife Fund Canada 2017). However, a comprehensive assessment has not been completed for all of southern Canada using common approaches and methods. The recently published framework to guide protected areas designations in Canada (Coristine et al. 2018) focuses on gaps in protected areas to guide the establishment of new parks and conservation lands, but does not integrate threats or the full range of biodiversity values 
(e.g. globally rare species) that many conservation groups are working to protect, particularly in southern Canada on the private land base. Global and North American conservation assessments that have included Canada (Olson and Dinerstein 2002; Ricketts et al. 1999) contextualize the importance of Canadian ecoregions from a broader conservation perspective but do not assess priorities from a Canadian context, such as national species at risk or connectivity between national parks, and do not use current national information on biodiversity, threat and conservation response.

A conservation assessment that ranks and prioritizes conservation in the ecoregions of southern Canada is needed to support measuring Canada's progress toward international biodiversity commitments including the Convention on Biological Diversity and Aichi Biodiversity Targets (2011-2020) (Secretariat of the Convention on Biological Diversity 2010). Reporting on biodiversity within ecoregions will provide greater resolution and consistent indicators to existing national reporting (e.g. ECCC 2018b). Perhaps most importantly, maps and information from a conservation assessment of southern Canada can provide Canadians with a better understanding of our country's biodiversity and most urgent conservation priorities.

\section{Methods}

Southern Canada was selected as the focus of the assessment because there are widespread and pervasive threats to biodiversity, and there is more comprehensive information. This area is predominantly under private land ownership, and has the greatest human influence index (Sanderson et al. 2002). Southern Canada is the most productive and biodiverse area of Canada and much of this areas is poorly represented in Canada's protected areas network (Andrew et al. 2011).

The study area was stratified by ecoregions based on Canada's ecoregion framework (Agriculture and Agri-Food Canada 1999; Marshall et al. 1999). Ecoregions are characterized by distinctive regional factors, including climate, physiography, soil and vegetation. These factors influence both biodiversity and land use with each ecoregion which makes them useful units of analysis for our study.

In total, 77 ecoregions are included in the analysis (Fig. 1). The study area includes all ecoregions south of the Boreal ecozones (Boreal Cordillera, Boreal Plains, Boreal Shield), plus 23 ecoregions in the southern Boreal ecozone and all ecoregions on the island of Newfoundland.

We identified three major categories for the assessment: biodiversity, threats to biodiversity and conservation responses. We then assembled datasets that could be used as measures for each category. Only datasets that were readily available, spatially referenced and with relatively uniform and comprehensive coverage across the study area as of August 2017 were used. Some important measures, such as connectivity, did not have a Canada-wide dataset and we completed separate analyses to create these datasets to include in the assessment.

We compiled and used 34 different measures in the analysis (Table 1). Within each of the three major categories, we then grouped similar measures into criteria. For example, the criterion of species richness (B1) is composed of two measures: species richness based on range maps (B1a) and species richness based on species tracked by Conservation Data Centres (B1b). 


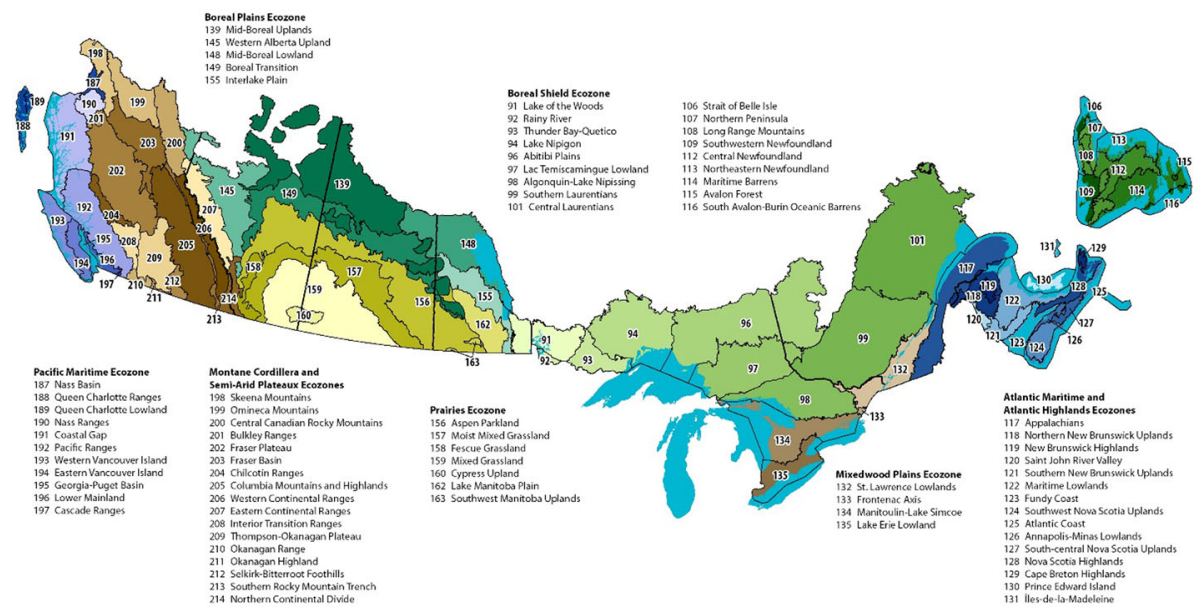

Fig. 1 Study area

To control for potential effects of ecoregion size on our measures we conducted a regression analysis where the raw values of each measure were regressed with ecoregion area. Where area had a significant effect on a measure, the residual variation from this relationship was extracted from the mean value of that measure and subsequently the raw values were replaced by the adjusted values. In all analyses, significance thresholds were set at an Alpha $=0.05$.

We then determined if any of our biodiversity, threat and conservation response measures were highly correlated with each other. Highly correlated measures are redundant in the analysis and could result in double-counting for the final score. We used three different statistical methods to determine this redundancy. First, we used a redundancy analysis to detect measures with significant collinearity (Legendre and Legendre 2012). Collinearity only arises because of how the measures are calculated and not because of real ecological relationships. Second, we used a cluster analysis to group measures that are similar to a degree that they can be regarded as a single measure (Legendre and Legendre 2012). Our final check to remove redundancy was a hierarchical cluster analysis based on Spearmanranked correlations to identify significant relationships between different measures. We then used the correlation matrix from the cluster analysis to visualize relationships between the measures and identify significant linear correlations (Zar 1999). The literature recommends $\mathrm{R}^{2}$ cut-off values ranging from 0.70 to 0.80 (Berry and Feldman 1985; Watts et al. 2015). Because higher degrees of collinearity do not necessarily translate into greater $R^{2}$ values (Berry and Feldman 1985), we used a conservative cut off value of $R^{2}=0.70$. Measures were removed from the analysis if two of the three statistical methods identified them as redundant. As a result, nine original measures were not included in the final analysis.

The scores were based on the value of the measure in comparison to other ecoregions. For three of the measures, natural cover, largest blocks of intact habitat and percentage protected areas, scores were based on assigned breaks to reflect recommended ecological thresholds or established conservation targets (see Table 1). But in most cases, the range of scoring values was classified into five natural breaks using the Jenks optimization method (ESRI 2012) and a numerical score of 1 (lowest) to 5 (highest) was applied to each 
Table 1 Measures and criteria used in the analysis to determine the total biodiversity score for each ecoregion ("Measures not used in final scoring as a result of the redundancy analysis)

Criteria/measures Description $^{\mathrm{a}}$

Biodiversity

B1 Total species richness

B1a Species richness based on range maps

B1b Species richness based on species tracked by Conservation Data Centres

B2 Richness of Canadian species at risk

B2a Richness of COSEWIC assessed wildlife species*

B2b Irreplaceability of COSEWIC assessed wildlife species*

B2c Richness of wildlife species that are candidates to be assessed by COSEWIC*

B2d Irreplaceability of COSEWIC candidate wildlife species*

B3 Richness of Species of Global Conservation Concern

B3a Globally vulnerable species*

B3b Irreplaceability of globally vulnerable species*

B4 Canada's conservation responsibility

B4a Richness of nationally endemic species

B4b Richness of species with high national conservation responsibility

B5 Richness of unique species

B5a Richness of species restricted to one ecoregion (range maps)

B5b Richness of species restricted to one ecoregion (tracked species)

B5c Richness of species with limited range*

B5d Beta-diversity of species

B6 Congregatory species

B6a Key biodiversity areas

B7 Intactness

B7a Natural cover
Total number of different species, based on range maps (mammals, birds, amphibians and trees) by ecoregion.

Total number of different species (all taxa) tracked by provincial Conservation Data Centres.

Total number of different COSEWIC assessed wildlife species (Endangered, Threatened, Special Concern) scored based on level of risk.

Each species scored based on number of occurrences.

Total number of different wildlife species that are candidates to be assessed by COSEWIC.

Each species scored based on number of occurrences.

Total number of different globally rare species (G1-G3/ T1-T3) scored based on rank.

Each species scored based on number of occurrences.

Each species scored based on number of occurrences.

Total count of species by ecoregion with $\geq 75 \%$ of range within Canada.

Global range was calculated for mammals, breeding birds and amphibians.

Trees based on North American range, which includes Canada, United States and Mexico.

Total number of species unique to one ecoregion based on range maps.

Total number of tracked species unique to one ecoregion.

Each species scored based on the inverse of the number of occurrences across all ecoregions.

Each species scored based on the inverse of the number of occurrences in adjacent ecoregions.

Area of Important Bird and Biodiversity Area within the ecoregion scored based on significance (global, continental, national) for congregatory species.

Percent of ecoregion in natural cover (including freshwater). Thresholds based on How Much Habitat is Enough (Environment Canada 2013). 
Table 1 continued

\begin{tabular}{cc}
\hline Criteria/measures & Description $^{\text {a }}$ \\
\hline B7b Intact mammal fauna & $\begin{array}{r}\text { Percent of ecoregion with areas including polygo } \\
\text { identified as intact mammal fauna (Morrison et a } \\
\text { Sanjayan et al. 2012). }\end{array}$ \\
B7c Size of largest block of intact habitat & $\begin{array}{r}\text { Number and extent of contiguous intact habitat b } \\
\text { based on habitat block analysis (Ricketts et al. }\end{array}$ \\
B7d Connectivity & $\begin{array}{r}\text { Percent of ecoregion containing corridors. Analy } \\
\text { completed for this study. }\end{array}$ \\
B8 Ecosystem distinctiveness & $\begin{array}{l}\text { Each land cover type scored based on number of } \\
\text { occurrences across all ecoregions. }\end{array}$ \\
B8a Distinctiveness of natural cover & Each land cover type scored based on number of \\
occurrences in adjacent ecoregions.
\end{tabular}

Threats

T1 Human footprint

T1a Human footprint*

T1b Change in human footprint

T2 Watershed Stress

T2 Watershed stress

T3 Risk index

T3a Conservation risk index

T3b Habitat risk index ${ }^{*}$

T4 Fragmentation

T4 Amount of habitat fragmentation

T5 Land use change

T5 Land use change

T6 Rate of climate change

T6a Mean temperature change

T6b Mean precipitation change

T6c Change in growing degree days

Mean grid value for ecoregion.

Mean percent change in grid value for ecoregion (1993 to 2009).

Cumulative sum of index values.

Habitat protected : habitat converted (terrestrial portion). Habitat natural : habitat converted (terrestrial portion).

Mean resistance value for ecoregion.

Conversion from natural cover to urban and cropland (2000-2010).

Rate of absolute change in mean temperature from the 1961-1990 and 1981-2010 climate normal period.

Rate of absolute change in mean precipitation (i.e. wetter or drier) from the 1961-1990 and 1981-2010 climate normal periods.

Rate of absolute change in the mean number of growing degree days from the 1961-1990 and 1981-2010 climate normal period.

T7 Lack of water

T7 Lack of water

Mean score for ecoregion based on water demand divided by water supply.

Conservation response

$\mathrm{R} 1$ protected areas

R1 Protected areas

Percent of ecoregion (terrestrial and inland waters) included in protected areas. Some thresholds based on Canada Target 1 (Environment and Climate Change Canada 2016).

R2 Representation 
Table 1 continued

\begin{tabular}{ll}
\hline Criteria/measures & Description $^{\text {a }}$ \\
\hline R2 Representation & $\begin{array}{l}\text { Mean percent of enduring landform features protected in } \\
\text { ecoregion (terrestrial portion). }\end{array}$ \\
\hline
\end{tabular}

${ }^{\text {aAdditional detail on data sources and analysis conducted for this study are included in the Supplementary }}$ Materials

measure. Scores of zero were used in measures with no values. For example, some ecoregions do not have any Key Biodiversity Areas and scored zero for this measure.

We then determined the final score for biodiversity and threat for each ecoregion using two different approaches. We summed each individual measure to produce final scores for biodiversity and threat. The final score was also determined based the sum of all measures within each criterion. The sum for each criterion was then rescaled back to a score from 1 to 5 using natural breaks. These rescaled scores were calculated for all criteria with multiple measures, and then the criteria scores were added together to produce a total score for each ecoregion.

To identify a threshold between higher and lower scoring ecoregions, the resulting total biodiversity and threat scores were each reclassified into five natural break categories. The threshold between the third- and fourth-highest categories was used to define ecoregions with higher relative total scores.

To identify the ecoregions with the higher biodiversity and threat values, the total scores for the both scoring approaches were combined, with the highest category from either approach taking precedence. Both approaches to sum the scores are equally valid, and a combined approach ensured that the highest scoring ecoregions would be identified. These were plotted on a scatter diagram divided into quadrants based on final scores for biodiversity and threat. Each ecoregion was then categorized into one of four groups based on these quadrants: higher biodiversity/higher threat, higher biodiversity/lower threat, lower biodiversity/higher threat and lower biodiversity/lower threat. This approach is based on the framework for identifying priority conservation areas using irreplaceability and vulnerability (Margules and Pressey 2000). Ecoregions were then further grouped within these quadrants based on their conservation response scores.

\section{Results}

\section{Biodiversity}

We identified 30 ecoregions with higher biodiversity scores relative to other ecoregions in the study areas (Fig. 2). These ecoregions are distributed across southern Canada and include Fundy Coast, Maritime Lowlands, Southern New Brunswick Uplands, Appalachians, St. Lawrence Lowlands, Lake Erie Lowland, Manitoulin-Lake Simcoe, Mid-Boreal Lowland, Mid-Boreal Uplands, Interlake Plain, Mixed Grassland, Eastern Continental Ranges, Northern Continental Divide, and Eastern and Western Vancouver Island. Ecoregions that ranked highest for biodiversity generally have greater species diversity or large areas that are important for congregatory birds. 


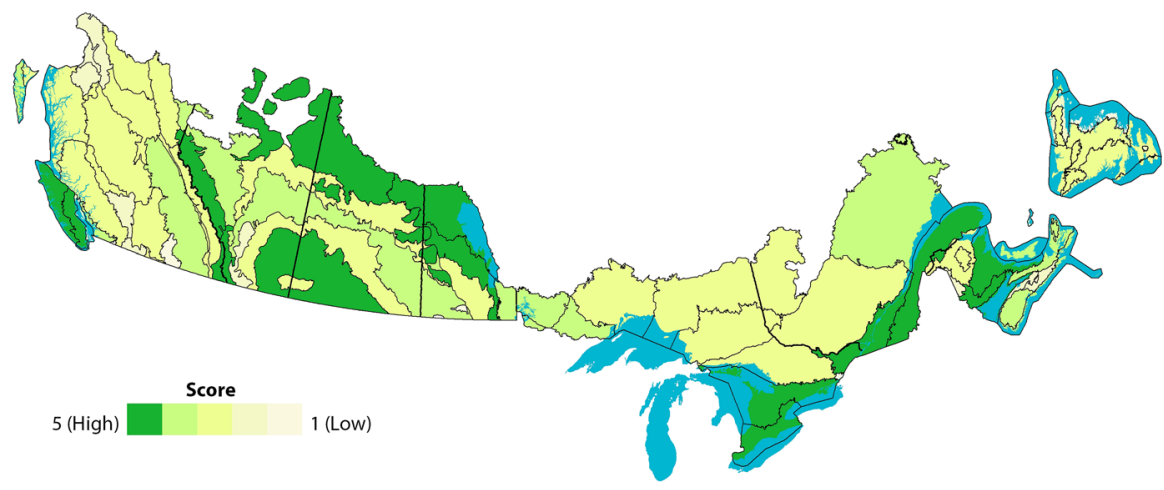

Fig. 2 Biodiversity scores by ecoregion

\section{Threat}

We identified 22 ecoregions with higher threat scores relative to other ecoregions in the study area (Fig. 3). Ecoregions with the highest overall threat scores include Lake Erie Lowland, Fescue Grassland and Manitoulin-Lake Simcoe. Ecoregions with the highest threat score are concentrated in geographies with the greatest amount of agriculture and settlement. This includes agricultural areas of the Maritimes (Annapolis and St. John's valleys, Prince Edward Island), southern Ontario and Quebec, the Prairies, the lower mainland of British Columbia and Eastern Vancouver Island. Ecoregions with the lowest total threat scores occur in the Boreal Shield and Boreal Plains ecozones and many of the mountain ecoregions of western Canada.

\section{Conservation response}

Only 16 ecoregions have higher scores for conservation response relative to other ecoregions in the study area (Fig. 4). Most ecoregions in southern Canada are not well represented in Canada's systems of parks and protected areas. Only 13 of 77 ecoregions meet Canada's national protected areas target of $17 \%$. These include Eastern Continental Ranges (67.7\%), Queen Charlotte Ranges (52\%) and Cape Breton (50\%). Most ecoregions that

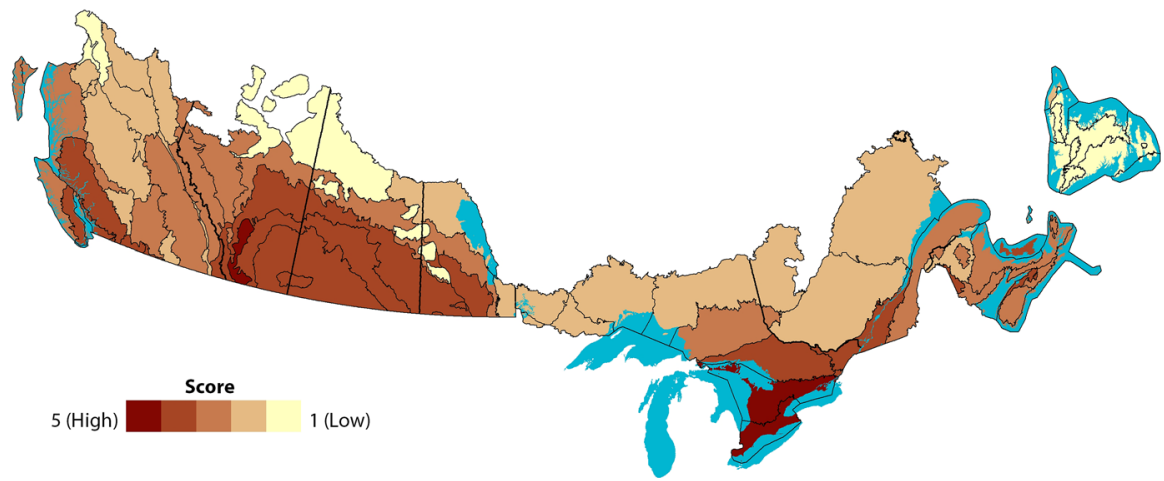

Fig. 3 Threat scores by ecoregion 


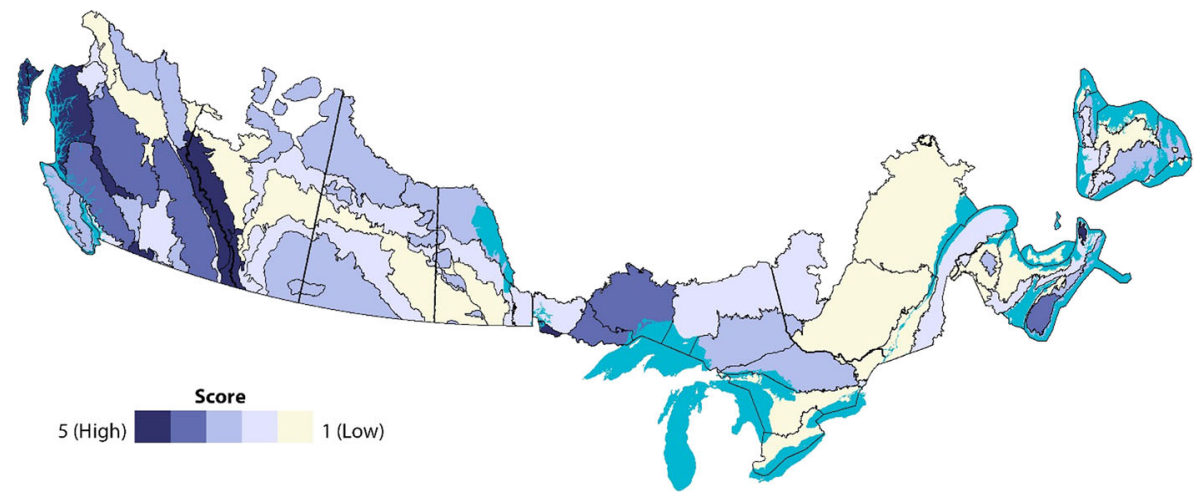

Fig. 4 Conservation response scores by ecoregion

scored in the highest categories for representation also scored high for amount of protected areas. However, the analysis reveals some ecoregions where protected areas appear to be under-representing the full diversity of landform features. Ecoregions with a higher score for total protected areas compared to representation include: Îles-de-la-Madeleine, Cascade Ranges, Selkirk-Bitterroot Foothills and Queen Charlotte Lowland.

\section{Crises ecoregions}

One of the goals of the assessment is to identify ecoregions in southern Canada in greatest need of immediate conservation action. We have defined this need based on higher biodiversity values and threats and refer these ecoregions as 'crisis ecoregions'. Our definition of crisis ecoregion builds on the original use of the term (Hoekstra et al. 2004), and subsequent applications (Watson et al. 2016) by incorporating biodiversity significance and an index of risk factors.

We identified nine crises ecoregions. These ecoregions rank in the highest categories for both biodiversity and threat compared to all other ecoregions in southern Canada (Fig. 5; Table 2).

These nine ecoregions represent $15.7 \%$ or $459,945 \mathrm{~km}^{2}$ of the study area, and only $4.6 \%$ of Canadian lands and inland waters. Over $60 \%$ of Canada's species at risk are found in these ecoregions. These nine ecoregions are distributed across Canada's most heavily settled landscapes (Fig. 6) and are home to $70 \%$ of the Canadian population. Five of these ecoregions are in the lowest category of percent protected and representation scores. This includes the three ecoregions in the Mixedwood Plains ecozone and the Prince Edward Island and Aspen Parkland ecoregions. The Lower Mainland, Mixed Grassland and Eastern Vancouver Island ecoregions also have lower conservation response scores. Only the Northern Continental Divide has a higher conservation response score. One of the key threats in this ecoregion is habitat fragmentation that could impact wildlife migration locally and within the broader context of the Yellowstone to Yukon corridor. 


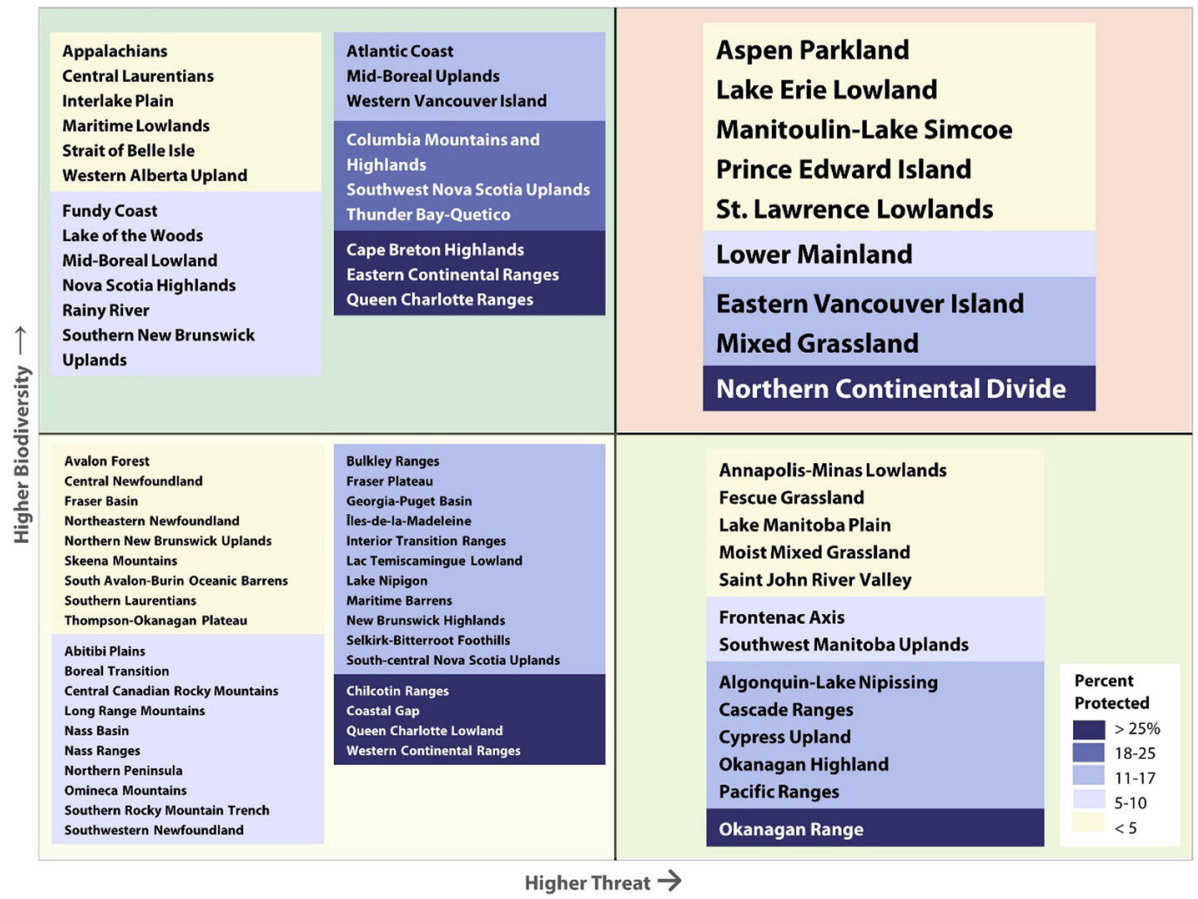

Fig. 5 Final categorization of ecoregions based on biodiversity and threat. Ecoregions with the highest total biodiversity and total threat scores are in the top right quadrant. Shading indicates the percentage of the ecoregion that is currently protected

\section{Other ecoregions}

A total of 21 ecoregions $\left(999,825 \mathrm{~km}^{2}\right.$ or $34.1 \%$ of the study area) score high for biodiversity but lower for threat. Six of these ecoregions have higher conservation response scores. They are generally located in the more intact northern and western portions of the study area, and along the east coast. Many of these ecoregions score very high for intactness, habitat diversity and congregatory species.

There are 13 ecoregions that score higher for threat but lower for biodiversity, these ecoregions represent a total of $301,365 \mathrm{~km}^{2}$ or $10.3 \%$ of the study area. Of these ecoregions, two (Pacific Ranges and Okanagan Range) have higher total conservation response scores with over $17 \%$ in parks and protected areas.

The remaining 34 ecoregions that represent $1,169,625 \mathrm{~km}^{2}$ or $39.9 \%$ of the study area fall in the lower left quadrant with lower biodiversity and lower threat. Four of these ecoregions, all located in western Canada, have over one-quarter of their lands and inland waters in protected areas. These ecoregions also score the highest category for representation of landform features in protected areas. 
Table 2 Descriptions of crisis ecoregions

\begin{tabular}{l} 
Ecoregion/provinces \\
\hline Aspen Parkland \\
Alberta, Saskatchew \\
Manitoba \\
\\
Eastern Vancouver \\
Island \\
British Columbia
\end{tabular}

\section{Lake Erie Lowland Ontario}

\section{Lower Mainland \\ British Columbia}

\author{
Manitoulin-Lake \\ Simcoe \\ Ontario
}

Mixed Grassland
Alberta, Saskatchewan

\section{Northern Continental Divide}

British Columbia, Alberta

Prince Edward Island Prince Edward Island

\section{Description}

Almost $80 \%$ of the natural cover has been converted to cropland and other land uses. Only $4 \%$ is included in conserved/protected areas and of this $0.7 \%$ is designated as community pasture. The rate of land conversion (2000-2010) in this ecoregion is one of the highest in southern Canada. The total population is $2,496,162$ (2016), with a growth of over $47.5 \%$ in the last 20 years

Just over $93 \%$ of this ecoregion remains in natural cover and $13.8 \%$ is within conserved/protected areas. Land use change in this ecoregion (2000-2010) was moderate. The land uses with the greatest net gain are settlement and roads. Major urban centres include Victoria, Nanaimo, Campbell River and Courtenay. The total population is 730,655 (2016), with a growth of $20 \%$ in the last 20 years

Only $14 \%$ of this ecoregion remains in natural cover and only $1 \%$ is within conserved/protected areas. The Lake Erie Lowlands ecoregion has experienced historic rates of habitat loss to agriculture and urban areas that are among the highest in Canada. Remaining habitat patches are generally small, highly fragmented and degraded. The total population is 8,324,391 (2016), with a growth of just over $29 \%$ in the last 20 years

Approximately $58 \%$ of this ecoregion remains in natural cover and $5.2 \%$ is within conserved/protected areas. There has been a moderate and steady expansion of urban areas in this ecoregion. The expansion of settlements has mostly occurred in areas that were previously forested, with a smaller amount expanding into croplands. The total population is 2,786,670 (2016), with a growth of $34 \%$ in the last 20 years

Almost $40 \%$ of this ecoregion remains in natural cover and only $1.9 \%$ is within conserved/protected areas. The ecoregion has experienced high historic rates of conversion of natural habitats to agriculture and urban areas. These have generally stabilized for the ecoregion, although there are still significant land use change pressures in some areas. The total population is 2,828,114 (2016), with a growth of just over $26 \%$ in the last 20 years

Approximately $42 \%$ of this ecoregion remains in natural cover and almost $11 \%$ is conserved/protected areas including $4 \%$ in community pastures. The rate of land conversion (2000-2010) in this ecoregion is one of the highest in southern Canada. This is primarily native managed grasslands being converted to cropland. The area of these grasslands decreased by $30 \%$, while the area of crop increased by about the same percentage. The total population (2016) is 204,767, with a growth rate of $7.8 \%$ since 1996

The Northern Continental Divide ecoregion is characterized by natural cover $(97 \%)$ with forestry dominating the working landscape. This ecoregion has one of the highest amounts of protected areas in southern Canada (29\%). The most significant threat to this ecoregion is habitat fragmentation that is caused by roads urban areas, and for some species, forestry. The total population is 46,694 (2016), with a growth of just under $20 \%$ in the last 20 years

Prince Edward Island has $56.4 \%$ natural cover; however, many of the forests are now even-aged stands. Approximately $3 \%$ of this ecoregion is within conserved/protected areas. The rate of land conversion (2000-2010) in this ecoregion is relatively low. There was an increase in the area of settlements (approximately 5.4\%) and while some cropland areas have expanded, others have reverted back to forest. The total population is 142,907 (2016), with a growth of just over $6 \%$ in the last 20 years 
Table 2 continued

\begin{tabular}{ll}
\hline Ecoregion/provinces & Description \\
\hline $\begin{array}{l}\text { St. Lawrence Lowlands } \\
\text { Ontario, Quebec }\end{array}$ & $\begin{array}{l}\text { Almost } 42 \% \text { of this ecoregion remains in natural cover and only } 3.7 \% \text { is within } \\
\text { conserved/protected areas. The St. Lawrence Lowlands ecoregion has } \\
\text { experienced high historic rates of conversion of natural habitats to agriculture } \\
\text { and urban areas. These have generally stabilized for the ecoregion as a whole, } \\
\text { although there are still significant land use change pressures particularly } \\
\text { around major urban areas and where soils are productive for agriculture. The } \\
\text { total population is 7,210,863 (2016), with a growth of just over 17\% in the last } \\
\text { 20 years }\end{array}$
\end{tabular}

St. Lawrence Lowlands Almost $42 \%$ of this ecoregion remains in natural cover and only $3.7 \%$ is within conserved/protected areas. The St. Lawrence Lowlands ecoregion has experienced high historic rates of conversion of natural habitats to agriculture and urban areas. These have generally stabilized for the ecoregion as a whole, arthough there are still significant land use change pressures particularly total population is $7,210,863$ (2016), with a growth of just over $17 \%$ in the last 20 years

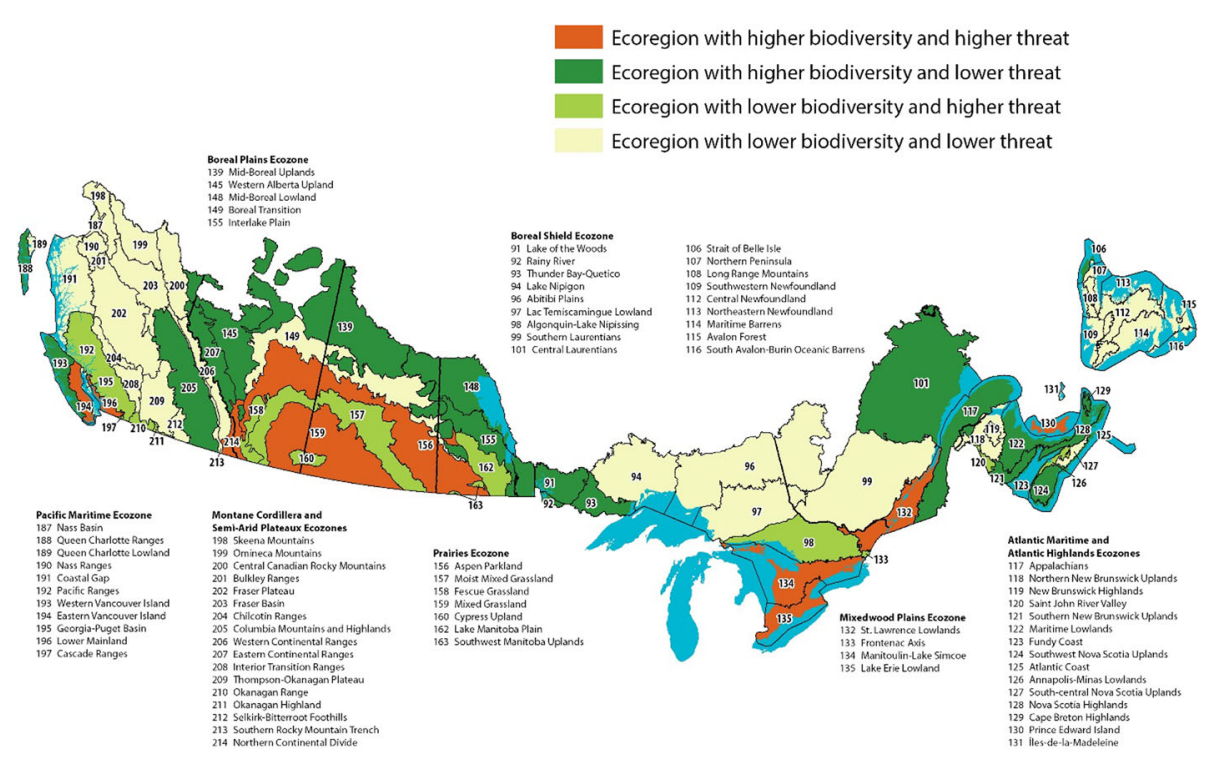

Fig. 6 Map of study area showing final categories of ecoregions based on total biodiversity and total threat score

\section{Discussion}

Our assessment supports conservation in Canada by providing a systematic framework to categorize ecoregions based on biodiversity, threat and conservation response. Although ecoregions with higher biodiversity and threat levels are generally known for southern Canada, and some have been identified in global and North American assessments (Olson and Dinerstein 2002; Ricketts et al. 1999), our analysis provides the first framework that assesses all ecoregions in southern Canada using a standardized approach.

Canada's nine crisis ecoregions have higher biodiversity and threats scores compared to other ecoregions in southern Canada and will be particularly challenging to manage for conservation. Five of the nine crisis ecoregions have less than $5 \%$ of their lands and inland waters in protected areas and the high level of threat represents the many competing land 
uses including agriculture, urban areas and resource development. Some of the existing protected areas within the crisis ecoregions may be too small or fragmented to maintain the biodiversity values for which they were established (e.g. Browne and Hecnar 2007). Many protected areas in the crisis ecoregions will also require active management and restoration to maintain their biodiversity and mitigate threats associated with small, fragmented nature reserves.

Results from our analysis can be used to help identify key regions to build clusters of effective habitat (Wiersma and Simonson 2010; Wiersma et al. 2004). Traditional government led protected areas can play and important role in these ecoregions but will need to be supported by Privately Protected Areas and Other Effective Area-based Conservation Measures, including conservation management agreements with landowners to maintain and restore biodiversity.

Only one of the nine crisis ecoregion that we identify, Northern Continental Divide, has over $17 \%$ of its lands and inland waters in protected and conserved areas. However, much of this protection is focussed in higher elevations and connectivity in the valley lands is highly restricted and under threat. The Northern Continental Divide and six of the other crisis ecoregions are located along Canada's southern border with the U.S., and conservation of species, ecosystems and connectivity will require transboundary conservation.

The analysis also identifies ecoregions in southern Canada that have higher biodiversity values but lower overall threat. Because these ecoregions often have a higher proportion of public lands and protected areas, many of them offer an opportunity to protect large and intact conservation networks. Some of these ecoregions include the $23 \%$ of the Earth's terrestrial surface that has not been significantly modified by the direct effects of human activities (Watson et al. 2018), including the Central Laurentians and Columbia Mountains and Highlands ecoregions. Protecting $17 \%$ has already been achieved in several higher biodiversity and lower threat ecoregions. In other ecoregions this can be accomplished through private and public land protection and Indigenous Protected and Conserved Areas.

The results of our assessment provide conservation practitioners with a framework to better contextualize conservation projects and to track progress toward national, regional and organizational conservation goals. It can provide a foundation to explore the feasibility, constraints, and opportunities to set and strive toward ecoregional-based conservation objectives and ensure that progress in meeting national targets occurs not just in the ecoregions where conservation can happen, but in the ecoregions where conservation must happen to protect Canadian biodiversity.

This assessment also provides a framework that could be applied to update Canada's 2010 Ecosystem Status and Trends Reporting (Federal Provincial and Territorial Governments of Canada 2010). The data and results are also complementary to existing national-scale monitoring initiatives including Canadian Environmental Sustainability Indicators, such as Canada's conserved areas (ECCC 2018b) and the World Wildlife Fund Living Planet Index for Canada (WWF Canada 2017) on national wildlife declines. The results support the identification of "shared priority places" under Canada's 2019-2022 Federal Sustainable Development Strategy (ECCC 2018a), and can help guide Canada's post-2020 biodiversity framework, including targets for the 2021-2030 UN Decade of Ecological Restoration.

In addition to monitoring and reporting at the ecoregional scale, the criteria used in the assessment could be used to develop new indicators for monitoring conservation in Canada. In particular, a conservation assessment can support Canada in reporting on key elements of Aichi Target 11, including connectivity, representation and 'areas of particular 
importance for biodiversity, and in developing post-2020 targets that focus on qualitative conservation measures (Lemieux et al. 2019).

The lens of ecoregions can help identify local actions that will contribute to biodiversity conservation from a Canadian context. Regional governments, land trusts and other conservation organizations can use this assessment to help coordinate conservation efforts in priority areas and demonstrate that resources are being directed to the areas that are of greatest importance and urgency for biodiversity conservation in Canada.

This assessment builds on past ecoregional assessments in southern Canada (e.g. Gratton 2010) and studies that have identified geographical gaps in conservation nationally (Iacobelli et al. 2006; Wiersma et al. 2009) and provincially (Freemark et al. 2006; Gauthier and Wiken 2003). The results can also support the current initiative to identify Key Biodiversity Areas (KBAs) in Canada (IUCN 2016). Ecoregions that have the highest score for species of global conservation concern and nationally endemic species have high probability of containing sites that could qualify under the KBA criterion for threatened species and geographically restricted biodiversity. These ecoregions include Appalachians, Fundy Coast and Eastern Vancouver Island. Ecoregions that have large habitat blocks, or large areas of natural cover compared could qualify as Key Biodiversity Areas the criterion for ecological integrity.

There are important elements of biodiversity that were not included in this study because they lack spatial information, occur at smaller geographical scales or have not yet been identified. Systematic biological surveys have not been conducted in many regions of the study area. The scoring system developed for this assessment was designed to be flexible and accommodate new measures and updated data. Additional measures that could be incorporated in the assessment as better data becomes available includes concentrations of migratory mammals or insects, range maps for additional species, richness of freshwater biodiversity and intact faunal assemblages for groups other than mammals. Information on nationally and globally rare or endemic vegetation communities does not yet exist because Canada's national vegetation classification system is incomplete, and vegetation communities are not tracked and ranked by many Conservation Data Centres. Better information on the distribution and status of vegetation communities, including current initiatives to identify Red List ecosystems (Ferrer-Paris et al. 2018; Rodríguez et al. 2015), would help support future iterations of this assessment.

Integration of additional socio-economic information into the analysis, such as forecasts on population trends, land value, and household income, could help to refine levels of risk and identify conservation opportunities. For example, Ontario's population is projected to increase by $38 \%$ by 2046 , with much of that growth focussed around the urban areas in the Lake Erie Lowland ecoregion (Ontario Ministry of Finance 2019).

Additional climate change models could be also considered to identify ecoregions most likely to continue to experience rapid changes in temperature, precipitation and other variables. Forecasting and mapping these potential future threats would help to identify those ecoregions that have the highest probability of experiencing future change and are in need of conservation action.

Our connectivity analysis did not incorporate models of potential species movements and habitat shifts due to climate change (e.g. Lawler et al. 2013). As additional information on projected species' range shifts, climate stability and potential climate refugia (Iwamura et al. 2010) become available and the certainty of these predictions increases, such data could help to refine the scoring of ecoregions.

Expanding our assessment to all of Canada would provide a more complete picture of biodiversity, threats and conservation needs, and national context for conservation actions. 
This assessment examines Canada's southern landscapes that have already been significantly altered and where conservation and often restoration are urgently needed. While parts of Canada's north are under pressure from industrial activities and climate change is rapidly altering the ecology of this region, there remains a globally significant opportunity to work with Indigenous Peoples to conserve large, intact landscapes. Although biodiversity data for some criteria is poorly documented in the north, there is information that would support the initial identification of important sites and networks. For example, the Athabasca sand dunes and the Beringia region of the Yukon are known to have high concentrations of at-risk, endemic and globally rare species.

Assessing the relative importance of biodiversity conservation over large scales is complex and depends on the measures and criteria that are applied (Brooks et al. 2006). Alternative approaches to our analysis could combine top scores based only on species measures or stratify the final scores based on ecozones. Applying the scoring that we developed to smaller scales based on ecological boundaries or a grid would refine the ecoregional results and help to pinpoint key sites for conservation action in each ecoregion. For example, Manitoba's Interlake Plain ecoregion has relatively higher biodiversity values, but lower threat. However, within a small area of this ecoregion are some of the world's best remaining remnants of tallgrass prairie. Other well-known areas of conservation concern were split between multiple ecoregions in our analysis, such as central British Columbia's South Okanagan Similkameen. These areas have very high numbers of species at risk and are critical to conserve biodiversity in Canada. Stepping down the scale of the analysis would support the identification of priority areas within all ecoregions will be an important next step.

Selecting priority places for conservation is difficult and is ultimately based on the species and ecosystems that we chose to value. Conserving biodiversity everywhere is also important. Protecting habitats and species across regional geographies protects representative biodiversity and is often critical in maintaining ecological services. But in a rapidly changing world with limited conservation resources, conservation requires decision making that is based on an assessment of priorities. This conservation assessment provides a framework to direct conservation actions to the ecoregions in southern Canada that have the highest levels of biodiversity and are under the greatest risk.

Acknowledgements The authors thank the many partners and agencies that provided data used in the assessment. Review of the methods and draft results were provided by Karen Beazley, Dalhousie University; Louise Gratton, Two Countries, One Forest Society; Dave Howerter, Ducks Unlimited Canada; Cathy Nielson, Environment and Climate Change Canada; Mike Patterson, International Institute for Sustainable Development; Dave Phillips, formerly Saskatchewan Ministry of Environment; Justina Ray, Wildlife Conservation Society Canada; Oscar Venter, University of Northern British Columbia; staff from the Nature Conservancy of Canada and several anonymous reviewers. Allan Edelsparre, University of Toronto, supported the statistical analysis, and Michael Bradstreet, Nature Conservancy of Canada, provided leadership and guidance for the project. Two anonymous reviewers provided valuable input that greatly improved our manuscript.

Data availability The datasets generated and analyzed for this study are available from the Nature Conservancy of Canada at: https://arcg.is/Cuz9n0.

\section{Compliance with ethical standards}

Conflict of interest The authors declare that they have no conflict of interest. 
Open Access This article is licensed under a Creative Commons Attribution 4.0 International License, which permits use, sharing, adaptation, distribution and reproduction in any medium or format, as long as you give appropriate credit to the original author(s) and the source, provide a link to the Creative Commons licence, and indicate if changes were made. The images or other third party material in this article are included in the article's Creative Commons licence, unless indicated otherwise in a credit line to the material. If material is not included in the article's Creative Commons licence and your intended use is not permitted by statutory regulation or exceeds the permitted use, you will need to obtain permission directly from the copyright holder. To view a copy of this licence, visit http://creativecommons.org/licenses/by/4.0/.

\section{References}

Agriculture and Agri-Food Canada (1999) A National Ecological Framework for Canada: Ecoregions. http:// sis.agr.gc.ca/cansis/nsdb/ecostrat/index.html

Anderson M, Vickery B, Gorman M, Gratton L, Morrison M, Mailet J, Kehm G (2006) The Northern Appalachian/Acadian Ecoregion: Ecoregional Assessment, Conservation Status and Resource CD. The Nature Conservancy, Eastern Conservation Science and the Nature Conservancy of Canada, Atlantic and Quebec regions. Boston

Andrew ME, Wulder MA, Coops NC (2011) Patterns of protection and threats along productivity gradients in Canada. Biol Conserv 144(12):2891-2901. https://doi.org/10.1016/j.biocon.2011.08.006

Berry WD, Feldman S (1985) Multiple regression in practice. Sage Publications, London

Brooks TM, Mittermeier RA, da Fonseca GA, Gerlach J, Hoffmann M, Lamoreux JF,.. . Rodrigues AS (2006) Global biodiversity conservation priorities. Science 313(5783):58-61

Browne CL, Hecnar SJ (2007) Species loss and shifting population structure of freshwater turtles despite habitat protection. Biol Conserv 138(3):421-429. https://doi.org/10.1016/j.biocon.2007.05.008

Coristine LE, Jacob AL, Schuster R, Otto SP, Baron NE, Bennett NJ, Woodley S (2018) Informing Canada's commitment to biodiversity conservation: a science-based framework to help guide protected areas designation through Target 1 and beyond. Facets 3(1):531-562. https://doi.org/10.1139/facets-20170102

COSEWIC (2016) Canadian Wildlife Species at Risk. http://www.registrelep.gc.ca/sar/assessment/wildlife_ species_assessed_e.cfm

Darwall WRT, Holland RA, Smith KG, Allen D, Brooks EGE, Katarya V, Vié J-C (2011) Implications of bias in conservation research and investment for freshwater species. Conserv Lett 4(6):474-482. https://doi.org/10.1111/j.1755-263X.2011.00202.x

Environment and Climate Change Canada [ECCC] (2014) Terrestrial biodiversity of federal interest in the Mixedwood Plains Ecozone of Ontario. Retrieved from https://www.ec.gc.ca/nature/default.asp?lang= En\&n=3B824EDF-1

Environment and Climate Change Canada (2016) 2020 Biodiversity goals and targets for Canada

Environment and Climate Change Canada [ECCC] (2018a) Achieving a sustainable future draft federal sustainable development strategy for Canada. Environment and Climate Change Canada, Gatineau

Environment and Climate Change Canada [ECCC] (2018b) Canadian Environmental Sustainability Indicators: Canada's conserved areas. www.canada.ca/en/environment-climate-change/services/ environmentalindicators/conserved-areas.html

Environment Canada (2013) How much habitat is enough? In. Environment Canada Toronto, Ontario

ESRI (2012) What is the Jenks optimization method? Accessed from https://support.esri.com/en/technicalarticle/000006743

Federal Provincial and Territorial Governments of Canada (2010) Canadian Biodiversity: Ecosystem Status and Trends 2010. Canadian Councils of Resource Ministers, In. Ottawa

Ferrer-Paris JR, Zager I, Keith DA, Oliveira-Miranda MA, Rodríguez JP, Josse C, Barrow E (2018) An ecosystem risk assessment of temperate and tropical forests of the Americas with an outlook on future conservation strategies. Conserv Lett 12(2):e12623

Freemark KE, Meyers M, White D, Warman LD, Kiester AR, Lumban-Tobing P (2006) Species richness and biodiversity conservation priorities in British Columbia, Canada. Can J Zool 84(1):20-31. https:// doi.org/10.1139/z05-172

Gauthier DA, Wiken EB (2003) Monitoring the conservation of grassland habitats, Prairie Ecozone, Canada. Environ Monit Assess 88(1-3):343-364

Gratton L (2010) Plan de conservation pour l'écorégion de la vallée du Saint-Laurent et du lac Champlain. Accessed from Montréal 
Habel JC, Teucher M, Mulwa RK, Haber W, Eggermont H, Lens L (2016) Nature conservation at the edge. Biodivers Conserv 25(4):791-799. https://doi.org/10.1007/s10531-016-1073-2

Henson BL, Riley JL, Brodribb KE (2005) Great Lakes conservation blueprint for terrestrial biodiversity. Nature Conservancy of Canada and Ontario Ministry of Natural Resources, Toronto

Hoekstra JM, Boucher TM, Ricketts TH, Roberts C (2004) Confronting a biome crisis: global disparities of habitat loss and protection. Ecol Lett 8(1):23-29. https://doi.org/10.1111/j.1461-0248.2004.00686.x

Iacobelli A, Alidina H, Blasutti A, Anderson C, Kavanagh K (2006) A landscape-based protected areas gap analysis and GIS tool for conservation planning. World Wildlife Fund, Toronto

IUCN (2016) Global standard for the identification of key biodiversity areas. Accessed from Gland, Switzerland

Iwamura T, Wilson KA, Venter O, Possingham HP (2010) A climatic stability approach to prioritizing global conservation investments. PloSone 5(11):e15103. https://doi.org/10.1371/journal.pone.0015103

Jenkins CN, Van Houtan KS, Pimm SL, Sexton JO (2015) US protected lands mismatch biodiversity priorities. Proc Natl Acad Sci USA 112(16):5081-5086. https://doi.org/10.1073/pnas.1418034112

Lawler JJ, Ruesch AS, Olden JD, McRae BH (2013) Projected climate-driven faunal movement routes. Ecol Lett 16(8):1014-1022. https://doi.org/10.1111/ele.12132

Legendre P, Legendre LF (2012) Numerical ecology. Elsevier, Amsterdam

Lemieux CJ, Gray PA, Devillers R, Wright PA, Dearden P, Halpenny EA, Beazley K (2019) How the race to achieve Aichi Target 11 could jeopardize the effective conservation of biodiversity in Canada and beyond. Mar Policy 99:312-323. https://doi.org/10.1016/j.marpol.2018.10.029

Margules CR, Pressey RL (2000) Systematic conservation planning. Nature 405:243-253. https://doi.org/10. 1038/35012251

Marshall I, Schut P, Ballard M (1999) A national ecological framework for Canada: attribute data. http://sis. agr.gc.ca/cansis/nsdb/ecostrat/index

McCune JL, Harrower WL, Avery-Gomm S, Brogan JM, Csergő A-M, Davidson LNK, Whitton J (2013) Threats to Canadian species at risk: an analysis of finalized recovery strategies. Biol Conserv 166:254-265. https://doi.org/10.1016/j.biocon.2013.07.006

McGuire JL, Lawler JJ, McRae BH, Nuñez TA, Theobald DM (2016) Achieving climate connectivity in a fragmented landscape. Proc National Acad Sci 113(26):7195. https://doi.org/10.1073/pnas.1602817113

Morrison JC, Sechrest W, Dinerstein E, Wilcove DS, Lamoreux JF (2007) Persistence of large mammal faunas as indicators of global human impacts. J Mamm 88(6):1363-1380

Natural Resource Management Ministerial Council (2010) Australia's Biodiversity Conservation Strategy 2010-2030. Accessed from Canberra

North American Bird Conservation Initiative (2012) The state of Canada's birds. Accessed from Ottawa

Olson DM, Dinerstein E (2002) The Global 200: priority ecoregions for global conservation. Ann Missouri Bot Garden 199-224

Ontario Ministry of Finance (2019) Ontario population projections, 2018-2046. Accessed from ontario.ca/finance, Toronto

Parks Canada (2016) State of Canada's Natural and Cultural Heritage Places. https://www.pc.gc.ca/en/docs/ pc/rpts/elnhc-scnhp

Ricketts TH, Dinerstein E, Olson DM, Eichbaum W, Loucks CJ, Kavanaugh K, Abell R (1999) Terrestrial ecoregions of North America: a conservation assessment, vol 1. Island Press, Washington

Riley J, Green S, Brodribb K (2007) A conservation blueprint for Canada's prairies and parkland. Accessed from Toronto

Rodríguez JP, Keith DA, Rodríguez-Clark KM, Murray NJ, Nicholson E, Regan TJ, Wit P (2015) A practical guide to the application of the IUCN Red List of Ecosystems criteria. Philos Trans R Soc B 370(1662):1-9. https://doi.org/10.1098/rstb.2014.0003

Runge CA, Watson JEM, Butchart SHM, Hanson JO, Possingham HP, Fuller RA (2015) Protected areas and global conservation of migratory birds. Science 350(6265):1255. https://doi.org/10.1126/science. aac9180

Sanderson EW, Jaiteh M, Levy MA, Redford KH, Wannebo AV, Woolmer G (2002) The human footprint and the last of the wild. Bioscience 52(10):891-904

Sanjayan M, Samberg LH, Boucher T, Newby J (2012) Intact faunal assemblages in the modern era. Conserv Biol 26(4):724-730

Secretariat of the Convention on Biological Diversity (2010) Global biodiversity outlook 3. https://www. cbd.int/doc/publications/gbo/gbo3-final-en.pdf

Trombulak S, Anderson M, Baldwin R, Beazley K, Ray J, Reining C, Gratton L (2008) The Northern Appalachian/Acadian Ecoregion: Priority Locations for Conservation Action. 
Venter O, Brodeur NN, Nemiroff L, Belland B, Dolinsek IJ, Grant JWA (2006) Threats to endangered species in Canada. Bioscience 56(11):903-910. https://doi.org/10.1641/0006-3568(2006)56[903: TTESIC]2.0.CO;2

Watson J, Jones KR, Fuller RA, Marco MD, Segan DB, Butchart SHM, Venter O (2016) Persistent disparities between recent rates of habitat conversion and protection and implications for future global conservation targets. Conserv Lett 9(6):413-421. https://doi.org/10.1111/conl.12295

Watson J, Venter O, Lee L, Jones KR, Robinson J, Possingham H, JAllan J (2018) Protect the last of the wild. Nature 563:27-30

Watts AG, Schlichting P, Billerman S, Jesmer B, Micheletti S, Fortin M-J,.. . Murphy MA (2015) How spatio-temporal habitat connectivity affects amphibian genetic structure. Front Genet 6:275

Wiersma YF, Nudds TD (2009) Efficiency and effectiveness in representative reserve design in Canada: the contribution of existing protected areas. Biol Conserv 142(8):1639-1646. https://doi.org/10.1016/j. biocon.2009.02.034

Wiersma Y, Simonson C (2010) Canadian national parks as islands: investigating the role of landscape pattern and human population in species loss. Park Sci 27(2):70-77

Wiersma YF, Nudds TD, Rivard DH (2004) Models to distinguish effects of landscape patterns and human population pressures associated with species loss in Canadian national parks. Landsc Ecol 19(7):773-786. https://doi.org/10.1007/s10980-005-3989-y

World Wildlife Fund Canada (2017) A national assessment of Canada's freshwater: watershed reports. Accessed from Toronto. http://assets.wwf.ca/downloads/WWF_Watershed_Reports_Summit_FINAL_ web.pdf

WWF Canada (2017) Living Planet Report Canada: a national look at widlife loss. World Wildlife Fund Canada, Toronto

Zar JH (1999) Biostatistical analysis, 4th edn. Prentice Hall, Upper Saddle River, NJ

Publisher's Note Springer Nature remains neutral with regard to jurisdictional claims in published maps and institutional affiliations.

\section{Affiliations}

\section{Daniel Kraus ${ }^{1,2}$ (D) Andrea Hebb ${ }^{1}$}

Daniel Kraus

dan.kraus@natureconservancy.ca

1 Nature Conservancy of Canada, 245 Eglinton Ave East, Suite 410, Toronto, Ontario M4P 3J1, Canada

2 School of Environment, Resources and Sustainability, Faculty of Environment, University of Waterloo, Environment 2, 200 University Avenue West, Waterloo, Ontario N2L 3G1, Canada 